\title{
TINGKILAN: EKSPRESI MASYARAKAT KUTAI DI TENGGARONG, KALIMANTAN TIMUR SEBUAH KAJIAN SENI WISATA
}

\author{
Meita Satyawati \\ Program Pascasarjana, Universitas Gadjah Mada \\ E-mail:meita_satya@yahoo.co.id
}

\begin{abstract}
Abstrak
Tingkilan merupakan salah satu bentuk seni pertunjukan tradisional di Tenggarong, Kalimantan Timur. Seiring dengan perkembangannya, Tingkilan menjadi dua jenis yaitu tradisional dan modern. Penelitian ini bertujuan untuk mengungkap keberlangsungan dan fungsi seni pertunjukan Tingkilan. Penelitian ini menggunakan metode kualitatif dengan pendekatan etnomusikologi, dan dibantu dengan ilmu antropologi musik dan sejarah. Data penelitian dianalisis secara tekstual dan kontekstual. Hasil penelitian menunjukkan, bahwa perubahan yang terjadi dalam musik Tingkilan dapat dilihat pada bentuk penyajiannya dari bentuk sederhana menjadi lebih variatif. Dalam masyarakat musik Tingkilan memiliki beberapa fungsi di antaranya sebagai hiburan, pemelihara solidaritas serta sebagai iringan tari. Campur tangan pemerintah daerah serta peran masyarakat membuat musik Tingkilan dapat bertahan sampai sekarang.
\end{abstract}

Kata kunci: Tingkilan, fungsi, perubahan, seni wisata

\section{TINGKILAN: EXPRESSION OF KUTAI SOCIETY IN TENGGARONG, EAST BORNEO, A STUDY OF TOURISM ART}

\begin{abstract}
Tingkilan is one of traditional performance arts in Tenggarong, East Kalimantan. It is also one of the local heritages which is still exist untill today. Nowadays, Tingkilan is divided into two types: traditional and modern one. The purpose of this study is to reveal the continuity and the function of Tingkilan. This study employs qualitative research using ethnomusicology approach, and antropology of music and culture. These approach helps in analizyng the data through textual and contextual data analisys. Moreover, theory of touristic arts is used to analize the change of Tingkilan music. The change can be found in the performances which are formed from simple one to more various one. In music society, Tingkilan is served as entertainment, solidarity maintenance and dance music. The local government and socety play an important role in maintaning Tangkilan music.
\end{abstract}

Keywords: Tingkilan, function, change, art of tourism

\section{PENDAHULUAN}

Tingkilan adalah salah satu kesenian tradisional yang masih hidup dan berkembang di Kutai Kertanegara terutama di kabupaten Tenggarong. Ada istilah musik melayu tetapi bagi masyarakat Kutai Tenggarong kesenian ini diberi nama Tingkilan. Secara etimologi Tingkilan berasal dari kata Tingkil yang berarti saling meningkah atau bersahut-sahutan. Biasanya dimainkan oleh dua orang atau lebih (wawancara Muhammad Arifin, Tenggarong pada tanggal 30 Maret 2010. ) Pada awalnya Tingkilan adalah pengisi waktu senggang setelah lelah bekerja seharian, dan sebagai rangkaian kegembiraan. 
Seiring berjalannya waktu, kesenian Tingkilan mengalami perkembangan dan melahirkan dua bentuk penyajian yaitu bentuk tradisional atau bisa disebut sebagai art by destination dan modern atau bisa disebut sebagai art by metamorphosis. Perubahan dan perkembangan bentuk kesenian dalam suatu masyarakat merupakan sesuatu yang wajar. Perkembangan bentuk dan pola penyajian musik Tingkilan makin terlihat seiring dengan bergulirnya era industri pariwisata yang ditandai dengan perencanaan program pariwisata oleh pemerintah Tenggarong.

Hadirnya pariwisata telah melahirkan seni pertunjukan yang telah mengalami perubahan bentuk kemasan yang semula bersifat tradisional menjadi kemasan pariwisata sebagai daya tarik untuk wisatawan. Hal ini menjadi salah satu hal yang menarik perhatian untuk mengetahui lebih lanjut tentang bagaimana perkembangan musik Tingkilan di Tenggarong, Kalimantan timur.

Pertunjukan musik Tingkilan merupakan perpaduan antara beberapa aspek penting yang menunjang seperti pemain, iringan, busana, tempat pentas, bahkan penonton, maka analisis teks dan konteksnya dari sebuah pertunjukan harus menggunakan pendekatan multidisiplin. Penelitian ini dilatar belakangi oleh disiplin ilmu etnomusikologi dan dibantu dengan beberapa disiplin ilmu yang lain dalam berbagai kebutuhan penelitian, metode, teori, konsep, sistem, dan sebagainya. agar mampu menjawab masalah pokok dalam penelitian diperlukan beberapa pendekatan bidang ilmu lain seperti antropologi musik, fungsi seni pertunjukan, sejarah, sosiologi, arkeologi seni. Oleh karena itu, landasan teori yang digunakan mencerminkan apa yang disebut sebagai pendekatan multidisiplin.

Pada perkembangannya musik Tingkilan mempunyai dua bentuk yaitu bentuk tradisional dan modern atau menurut J. Maquet dalam tulisan Soedarsono yang berjudul "Industri Pariwisata Sebuah Tantangan dan Harapan bagi Negara Berkembang (1993)" yang mengutarakan bahwa hadirnya masyarakat wisata disebuah daerah, maka akan lahir bentuk lain selain yang sudah ada. Teori ini digunakan untuk menganalisis sejauh mana perkembangan musik Tingkilan yang berubah dari seni tradisional atau bisa disebut art by destination yakni seni yang telah ada merupakan produk masyarakat yag hasilnya dipergunakan dengan seiring waktu karena mengikuti perkembangan dan adanya industri pariwisata berubah menjadi art by methamorphosis/tourist art.

Mengungkap aspek tekstual atau analisis musik Tingkilan penulis menggunakan dasar analisis musik yang dikemukakan. Untuk mengungkap bagaimana unsur-unsur musik dalam pertunjukan Tingkilan digunakan teori dari Bruno Nettl, bahwa dua hal yang harus diperhatikan dalam bentuk musik yaitu: (1) mengenali unsur-unsur musik yang menjadi tema sebuah komposisi; (2) mengenali keterkaitan dan hubungan antara bagian-bagian, frase-frase dan motif-motif dalam sebuah komposisi (Nettl, 1964: 146). Penulis berharap dengan teori yang dikemukakan Bruno Nettl sedikit banyak bisa mempermudah dalam menganalisis musik Tingkilan.

Teori yang tidak kalah pentingnya untuk dijadikan sebagai landasan berfikir adalah teori fungsi Alam P. Merriam menyatakan bahwa etnomusikologi merupakan disiplin ilmu yang mempelajari musik yang bukan saja menganalisis musik secara struktural, melainkan juga melihat fungsi musik dalam situasi sosial. Selanjutnya dikatakan dalam bukunya The Antropology of Music bahwa fungsi musik terdiri dari: (1) fungsi musik sebagai kenikmatan estetis; (2) fungsi musik sebagai iringan; (3) fungsi musik sebagai komunikasi; (4) fungsi sebagai menggambarkan simbolik; (5) fungsi musik sebagai respon fisik; (6) fungsi musik sebagai penyelenggaraan kesesuaian dengan norma-norma sosial; (7) fungsi musik sebagai pengesahan lembaga sosial dan ritual religius; (8) fungsi musik sebagai penopang kesinambungan dan stabilitas kebudayaan; dan (9) fungsi musik untuk penopang integrasi sosial; (10) pengungkapan emosional.

Fungsi musik Tingkilan mengalami prekembangan dari bentuk yang sederhana menjadi lebih variatif. Musik Tingkilan yang muncul di Tenggarong dapat dianalisis 
dengan menggunakan ciri-ciri seni wisata yang dikemukakan oleh R.M. Soedarsono, yang disebutkan memiliki ciri-ciri: (1) tiruan dari aslinya; (2) singkat dan padat; (3) penuh variasi; (4) ditanggalkan nilai-nilai sakral, magis, serta simbolnya; (5) murah harganya/terjangkau kantong wisatawan (Soedarsono, 1999:3).

\section{METODE}

Penelitian ini tergolong ke dalam penelitian kualitatif dengan mengunakan metode penulisan secara deskriftif analitis dan menggunakan pendekatan etnomusikologi. Oleh karena itu untuk mewujudkan obyek yang dipilih ke dalam bentuk tulisan deksriftif analisis. Lokasi penelitian yaitu di kota Tenggarong kutai Kertanegara. Informan yang dipilih dalam penelitian ini adalah tokoh seniman di tenggarong, pemusik, penari, pegawai dinas pariwisata dan masyarakat tenggarong.

Metode pengumpulan data yang digunakan dalam penelitian ini bermacam-macam bentuknya, mulai dari pengumpulan materi yang berwujud tulisan tentang Tingkilan, bahasa atau kata-kata dan tidakan merupakan sumber data yang utama yang bersifat pengamatan dan wawancara. Sumber data ini dapat dicatat melalui catatan tulisan, pengambilan foto, pengambilan video, dan pengambilan audio pada saat latihan dan pementasan. Dan beberapa sumber data kualitatif yang digunakan yaitu: penelitian lapangan, wawancara, studi pustaka dan dokumentasi.

\section{HASIL DAN PEMBAHASAN}

Tingkilan menurut masyarakat pemiliknya memiliki beberapa pengertian salah satunya adalah Tingkilan berasal dari kata Tingkil yang berarti saling meningkah atau bersahut-sahutan. Musik Tingkilan biasanya dapat dibawakan sendiri maupun berkelompok. (wawancara Muhammad Arifin, Tenggarong pada tanggal 30 Maret 2014). Dan ada pula yang menyebutkan bahwa Tingkilan berasal dari dua kata Tingkil yang berarti sindir. Penggunaan akhiran -an berarti sindiran. Musik Tingkilan yang dibawakan sendiri biasanya hanya membawakan cerita tentang legenda, keindahan alam, dan nasehat. Pada mulanya musik Tingkilan dimainkan untuk mengisi suasana sepi. Baru kemudian menjadi tontonan yang kadang kala dipertunjukkan untuk mendapat hiburan dalam segala kesumpekan yang terjadi pada para individu dan masyarakat.

Bagi masyarakat Kutai musik Tingkilan merupakan penggambaran hidup mereka dan merupakan kesenian yang harus dilestarikan. Dalam setiap kesempatan mereka memainkan musik Tingkilan sebagai hiburan. Lagu yang biasa dibawakan berupa pantun yang biasanya secara spontan atau berdasarkan kondisi dan sifat acara tersebut. Musik ini pun masih ada sampai sekarang dan masih sering dimainkan disetiap ada kesempatan. Bagi masyarakat Kutai musik Tingkilan begitu dikagumi oleh masyarakat hingga ketika ada pentas musik Tingkilan, orang-orang tua akan datang untuk menontonnya. Disitulah pentas musik Tingkilan kemudian menjadi sebuah media komunikasi masyarakat yang bisa mempertemukan antara personal dengan personal lainnya. Masyarakat tentu saja bisa menjadikan manusia yang berintegrasi dengan manusia yang lain, sehingga bisa terhindar dari konflik sosial yang tidak diinginkan.

Musik Tingkilan dalam fungsi sosial misalnya, daya tarik seni tradisi terletak pada kemampuannya sebagai pembangun dan pemelihara solidaritas kelompok. Dari berbagai pertunjukannya, masyarakat dapat memahami kembali nilai-nilai dan pola perilaku yang berlaku dalam lingkungan sosialnya. Dalam kiprahnya, musik Tingkilan pun memiliki peran tersebut. Hal itu terlihat dalam setiap penyajian lagu-lagu yang dibawakan, selalu menggunakan kata-kata sindiran atau kritik atas fenomena yang terjadi dalam kehidupan masyarakat. Musik Tingkilan juga berfungsi sebagai iringan tari, suatu pertunjukan tari tanpa musik maka pertunjukan tidak akan berjalan. musik tingkilan sebagai iringan tari jepen berperan sebagai pengiring gerak tari yang ditampilkan. Saat ini bentuk pertunjukan musik Tingkilan mengalami sebuah perkembangan. Perkembangan tersebut pada perubahan bentuk pertunjukannya: 
Tabel 1. Perbandingan musik Tingkilan tradisional dan modern

\begin{tabular}{lll}
\hline \multicolumn{1}{c}{$\begin{array}{c}\text { Aspek yang } \\
\text { dibandingkan }\end{array}$} & \multicolumn{1}{c}{ Musik Tingkilan Tradisional } & \multicolumn{1}{c}{ Musik Tingkilan Modern } \\
\hline Bentuk Penyajian & $\begin{array}{l}\text { Berbalas pantun, dan menggunakan bahasa } \\
\text { kutai. Isi pantun diutamakan dan musik } \\
\text { sebagai pengiring }\end{array}$ & $\begin{array}{l}\text { Tidak ada berbalas patun, yang } \\
\text { dibawakan sudah berbentuk } \\
\text { lagu. Musik lebih diutamakan }\end{array}$ \\
\hline Vokal & Cempreng (tipis) & Tebal \\
\hline Alat musik & Gambus dan Rebana & $\begin{array}{l}\text { Gambus, Cello, Bas, Ukulele, } \\
\text { keybord }\end{array}$ \\
\hline Durasi & $\begin{array}{l}\text { Tidak terpatok waktu hanya berdasarkan } \\
\text { kebutuhan }\end{array}$ & Durasi sebuah lagu 3-4 menit \\
\hline Penonton & Berinteraksi dengan pemusik & Hanya sebagai penonton \\
\hline Busana dan rias & $\begin{array}{l}\text { Pakaian melayu, laki-laki menggunakan baju } \\
\text { lengan panjang, celana panjang, sarung diikat } \\
\text { di pinggang. Perempuan baju kurung. Dan } \\
\text { sanggul cepol }\end{array}$ & $\begin{array}{l}\text { Baju taqwo untuk perempuan, } \\
\text { baju miskat untuk laki-laki }\end{array}$ \\
\hline $\begin{array}{l}\text { Tempat } \\
\text { Pementasan }\end{array}$ & $\begin{array}{l}\text { Dirumah, halaman, lapangan atau rumah } \\
\text { pejabat }\end{array}$ & Gedung, lapangan, hotel \\
\hline
\end{tabular}

Musik Tingkilan merupakan salah satu jenis kesenian tradisional masyarakat Kutai telah dipersiapkan menjadi sebuah kemasan yang diperuntukan bagi hiburan pariwisata. Penyesuaian yang dilakukan untuk jenis hiburan tersebut sudah dilakukan oleh para senimannya baik dalam segi instrumentasinya maupun lagulagunya yang dinyanyikan. Inovasi dalam setiap grup musik Tingkilan memberikan nuansa yang baru bagi perkembangannya. Seperti yang telah dirumuskan oleh Tomars bahwa kemasan seni wisata memiliki ciri-ciri, yaitu (1) tiruan dari aslinya; (2) singkat dan padat; (3) penuh variasi; (4) ditanggalkan nilai-nilai sakral, magis, serta simbolnya; (5) murah harganya/terjangkau kantong wisatawan (Soedarsono, 1999:3).

\section{Tiruan dari Bentuk Aslinya}

Bentuk Tingkilan yang baru dalam kemasan seni wisata tentunya berbeda dengan bentuk aslinya.Kenyataan ini memang suatu yang tidak mudah untuk dihindari. Pada sisi lain bentuk ini akan sangat berguna bagi perkembangan musik tradisi di Kalimatan Timur, terutama musik Tingkilan. Suatu hal yang penting untuk diperhatikan, jangan sampai bentuk baru ini menghilangkan ciri khas tradisi dan budaya yang melingkupinya, sehingga perkembangan musik tersebut tidak merubah esensi nilai yang dikandungnya dan tidak merubah ciri khas daerah dimana musik tersebut lahir dan berkembang.Inilah yang dimaksud dengan tiruan dari bentuk aslinya, yaitu musik Tingkilan berkembang dengan bentuknya yang baru dalam kemasan seni wisata sebagai transformasi nilainilai luhur budaya pemiliknya.

\section{Singkat dan Padat}

Sebelum musik Tingkilan dikemas menjadi sebuah kemasan seni wisata, atau ditampilkan sebagai kemasan seni tradisi, musik tersebut mempunyai durasi yang panjang. Solusi dari permasalahan ini dilalui dengan memendekkan durasi pertunjukan musik atau mempersingkat waktu pementasannya dengan cara mengurangi syair-syair yang panjang, membuat lagu baru yang lebih pendek dari bentuk aslinya, dan memadatkan bentuk garapan atau menonjolkan aransemen musik tersebut. Perbandingan antara sebuah pertunjukan yang dilakukan selama beberapa jam dipersingkat menjadi beberapa menit untuk lebih mengefesienkan waktu yang digunakan. Musik Tingkilan tidak lagi dinikmati sebagai sebuah guyonan atau cerita dalam 
pergaulan masyarakat remaja Kalimantan Timur, tetapi dinikmati sebagai wahana atau sajian seni yang mengandung nilai estetis tinggi.

\section{Variatif}

Penyajian musik Tingkilan tidak seperti dulu lagi yang bersifat monoton, sekarang dalam penyajiannya sudah ditambahkan dengan alat musik Barat dan jenis lagu yang kaan sudah bernuansa pop, dangdut, dan keoncong. Akan tetapi tetap kemasan ini tidak meninggalkan tradisi aslinya, yaitu dengan memainkan pantun-pantun yang sudah diaransemen menjadi sebuah lagu. Disamping itu bentuknya yang variatif dapat dilihat dari bentuk garap lagu yang ditampilkan. Bentuk musik yang baru lebih bernuansa modern dengan menonjolkan efektifitas pengembangan permainan instrument secara tunggal seperti gambus, meskipun permainan instrument lain turut diperhatikan dalam pembentukan harmoni yang ditampilkan. Bersama bentuknya yang baru musik ini lebih terlihat kretif dan hidup.

\section{Unsur Ritual Sudah Hilang}

Musik Tingkilan ini pada awalnya hanya sebagai musik hiburan, sehingga walau dapat pengembangan musik tersebut hanya dipertunjukan untuk tujuan menghibur karena dari awal musik Tingkilan produk lama dan baru bersifat hiburan semata. Berbeda dengan kesenian yang dimiliki suku pedalaman yang masih mengandung unsur ritual masih sangat kuat dan kental.

\section{Murah Harganya}

Pengemasan musik sebagai seni wisata tidak hanya memperhitungkan perkembangan dari dalam, melainkan juga perkembangan dari luar, seperti perhitungan dana penggarapan dan dana pementasan bagi setiap penonton. Perhitungan dana penggarapan akan dipermurah, karena tidak menggunakan waktu yang terlalu lama. Kemasan kesenian Tingkilan produk lama memerlukan banyak orang, sehingga memerlukan pembiayaan yang mahal. Sedangkan penekanan pembiayaan tiket pertunjukan untuk penonton, memang perlu sekali dilakukan agar pertunjukan itu dapat dilihat oleh siapa saja, dalam arti pertunjukan kesenian Tingkilan sebagai hiburan dapat dijangkau oleh kocek semua orang, sehingga nantinya kesenian ini tidak saja dapat dinikmati sebagai hiburan seni wisata oleh wisatawan, tetapi juga oleh masyarakat pendukungnya sendiri.

\section{KESIMPULAN}

Bagi masyarakat Kutai musik Tingkilan merupakan penggambaran hidup mereka dan merupakan kesenian yang harus dilestarikan. Dalam setiap kesempatan mereka memainkan musik Tingkilan sebagai hiburan. Lagu yang biasa dibawakan berupa pantun yang biasanya secara spontan atau berdasarkan kondisi dan sifat acara tersebut. Musik ini pun masih ada sampai sekarang dan masih sering dimainkan disetiap ada kesempatan. Fungsi Tingkilan dalam masyarakat sebagai hiburan, media komunikasi masyarakat yang bisa mempertemukan antara personal dengan personal lainnya., kepuasan estetis, fungsi sosial dan sebagai iringan tari

Saat ini bentuk pertunjukan musik Tingkilan mengalami sebuah perkembangan. Perkembangan tersebut pada perubahan bentuk pertunjukannya. Perubahan bentuk pertunjukan terjadi dalam musik Tingkilan. Dalam penyajian musik Tingkilan tradisional saling berinteraksi dengan Dalam penyajian musik Tingkilan modern sudah tidak lagi mengenal berbalas pantun yang ada hanya menampilkan sebuah pertujukan untuk penonton. Bentuknya sudah berubah, dengan penambahan alat, seperti cello, bass, cak cuk. Rebana tidak digunakan lagi digantikan dengan alat musik yang lebih modern untuk mengisi warna suara. Variasi musik menjadi salah satu daya tarik musik Tingkilan modern. Genre musik yang dibawakan bertambah lagu khas Kutai tapi juga dangdut, barat, pop tetapi dengan gaya khas Tingkilan.

Upaya pemeliharaan musik tradisi yang merupakan warisan leluhur dari nenek moyang merupakan kewajiban generasi penerus yang perlu mendapat prioritas. Jika tidak, maka pada suatu saat akan punah. Dalam mengupayakan pemeliharaan tersebut selain peran masyarakat pemilik, peran pemerintah juga dibutuhkan. 
Peran pemerintah kota Tenggarong dalam melestarikan budaya yang ada sangat besar. Salah satu program dinas pariwisata adalah memperkenalkan musik Tingkilan kepada masyarakat luas di hotel-hotel sebagai musik penyambut selamat datang. Dinas pariwisata membuat jadwal untuk grup-grup yang ada di Tenggarong.Setiap minggu grup yang tampil berbeda-beda, setiap kesempatan mereka bermain pagi dan sore hari secara bergantian. Mengadakan pelatihan-pelatihan dan mengirim kontingen seni kebeberapa even-even nasional maupun internasional untuk dapat lebih mengenalkan musik Tingkilan.ini merupakan salah satu dari cara dinas Pariwisata Tenggarong untuk memajukan budaya dan pariwisata.

\section{DAFTAR PUSTAKA}

Aini, Mohd dkk. 1979. Naskah Seni Budaya dan Latar Belakang Sejarahnya daerah Kabupaten Kutai. Samarinda: Departemen Pendidikan dan Kebudayaan.

Asrani. 1993. Tingkilan Musik Tradisional Kaltim. Samarinda: Taman Budaya Kalimanatan Timur.

Azmidi. 2010. "Erau” Tradisi dan Ritual Kesultanan Kutai Kertanegara. Tenggarong: Dinas Kebudayaan dan Pariwisata.

Idris, Zaelani. 1999. Obyek Perkembangan Kesenian Tradisional di Kalimantan Timur. Tenggarong: Humas Setwilda Tk. II Kutai.
Idris, Zaelani. 1976. Kumpulan Naskah Kesenian Tradisional Kalimantan Timur. Samarinda: Taman Budaya Propinsi Kaltim.

Merriam, Alan P. 1964. The Anthropolgy of Music. Chicago: Nort Westren University Press.

Prier, Karl Edmund. 2004. Ilmu Bentuk Analisis. Yogyakarta: Pusat Musik Liturgi.

Rosyadi, Imron M. 2001. Sekilas Adat Budaya Kalimantan Timur. Samarinda: Humas Pemprov Kaltim.

Rosyadi, Imron M. 2002. Seni Pertunjukan Indonesia di Era Globalisasi. Yogyakarta: Gajah Mada University Press.

Soedarsono, R. M. 1999. Seni Pertunjukan Indonesia dan Pariwisata. Bandung: MSPI dan Arti.

Soedarsono, R. M. 2002. Seni Pertunjukan Indonesia di Era Globalisasi. Yogyakarta: Gajah Mada University Press.

Syahbandi dkk. 1992. Dampak Pengembangan Pariwisata terhadap Kehidupan Budaya daerah di Kalimantan Timur. Samarinda: Departemen Pendidikan dan Kebudayaan Kaltim. 